\title{
Affective Decision-Making Is Predictive of Three-Month Relapse in Polysubstance-Dependent Alcoholics
}

\author{
Bieke De Wilde ${ }^{a-c}$ Antonio Verdejo-García ${ }^{d}$ Bernard Sabbe ${ }^{b, c}$ \\ Wouter Hulstijn $^{\text {b, e }}$ Geert Dom ${ }^{a-c}$ \\ a Psychiatrisch Centrum Broeders Alexianen, Boechout, ${ }^{b}$ Collaborative Antwerp Psychiatric Research Institute, \\ Universiteit Antwerpen, ' Universiteit Antwerpen, Antwerp, Belgium; ${ }^{\mathrm{d} D e p a r t m e n t}$ of Clinical Psychology and

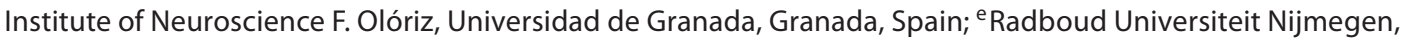 \\ Nijmegen, The Netherlands
}

\section{Key Words}

Affective decision-making $\cdot$ Polysubstance-dependent alcoholics $\cdot$ Relapse

\begin{abstract}
Background/Aims: Common and long-lasting deficits in decision-making in polysubstance-dependent alcoholics (PSA) reflect neurobiological alterations that define the chronic nature of addiction. These deficits affect goal-directed behavior and might be critical risk factors predicting relapse in PSA. Methods: The Delay Discounting Task (DDT) and the lowa Gambling Task (IGT) assessed the delay-discounting and decision-making skills among 37 abstinent PSA. Results: The findings indicated that IGT but not DDT performances were associated with 3-month abstinence, irrespective of the influence of personality traits and coexistent medications. Conclusion: The results show that the IGT, which assesses processes that are important in the latter stages of addiction, is ecologically more valid compared to the DDT, which assesses processes important in the early stages. They underline the importance of using neurocognitive measures to identify high relapse risk patients and emphasize the relevance of promoting new treatments.
\end{abstract}

Copyright ๑ 2012 S. Karger AG, Basel

\section{KARGER}

Fax +4161306 1234

E-Mail karger@karger.ch

www.karger.com
(C) 2012 S. Karger AG, Basel

$1022-6877 / 13 / 0191-0021 \$ 38.00 / 0$

Accessible online at:

www.karger.com/ear

\section{Introduction}

The identification of risk factors predicting drug relapse is pivotal for detecting patients in need of specialized treatment interventions, i.e. better focused relapse prevention strategies, and developing new treatment interventions targeted at this high-risk populations. A vast literature on prediction of relapse that classified the key predictors of alcohol relapse into four broad categories, sociodemographic (e.g. socioeconomic or employment status), clinical (e.g. comorbid psychopathology), psychological (e.g. self-report measures of impulsive personality, craving or stress), and cognitive (e.g. neurocognitive measures of decision-making and impulsivity) [1]. In the last years, the treatment literature [2-4] has paid particular attention to cognitive predictors because they offer a number of advantages over other predictors. Particularly, they are thought to reflect better the neurobiological alterations that define the chronic nature of addiction, and they are significantly associated with other risk factors, such as impulsivity, comorbid psychiatric disorders, or craving [5].

Addicted individuals, irrespective of the main drug of choice, share generalized cognitive-executive deficits [6]. 
Table 1. Alcohol and drug use

\begin{tabular}{|c|c|c|c|}
\hline & $\begin{array}{l}\text { Age } \\
\text { of onset }\end{array}$ & $\begin{array}{l}\text { Years of sub- } \\
\text { stance use }\end{array}$ & Range \\
\hline Alcohol $(\mathrm{n}=31)$ & $19.45 \pm 5.74$ & $11.48 \pm 6.96$ & $1-7.5$ l/day \\
\hline Cocaine $(n=21)$ & $23.67 \pm 7.41$ & $5.95 \pm 4.03$ & $0.5-70 \mathrm{~g} /$ week \\
\hline \multicolumn{4}{|l|}{ Amphetamines } \\
\hline$(\mathrm{n}=26)$ & $18.96 \pm 5.25$ & $7.19 \pm 4.96$ & $1-30 \mathrm{~g} /$ week \\
\hline Cannabis $(\mathrm{n}=29)$ & $17.00 \pm 4.65$ & $11.79 \pm 7.43$ & 5-25 g/week \\
\hline $\operatorname{MDMA}(\mathrm{n}=24)$ & $20.25 \pm 6.88$ & $5.38 \pm 4.14$ & $\begin{array}{c}\text { 5-30 tablets/ } \\
\text { week }\end{array}$ \\
\hline
\end{tabular}

Patients used on average $4.89 \pm 2.01$ substances. Substances were mentioned when at least half of the group abused them.

However, deficits in delay-discounting, i.e. the ability to hold the subjective value of reinforcers even when their delivery is delayed, and decision-making, i.e. the ability to select long-term adaptive choices at the expense of risky options that offer a 'superficially seductive' gain, are particularly long-lasting [7-9]. They are also tightly linked to durable neurobiological abnormalities, which persist in polysubstance abusers after 2-4 years of abstinence [10]. Therefore, they are optimal candidates for predicting drug relapse outcomes after the treatment. These skills are also critical for the integration of cognitive and emotional input that guide goal-directed behavior towards long-term outcomes [11]; therefore, their concourse may be fundamental to resisting the influence of well-known affective triggers of relapse, such as stress [12] and states of positive or negative mood [13]. In agreement with these notions, available studies have shown that impaired decision-making is predictive of relapse in alcohol and opiate-dependent patients. It was found that alcohol- and opiate-dependent patients with impaired performance on the Iowa Gambling Task (IGT) [14] and the Cambridge Gamble Task (CGT) [15] were more likely to relapse after three months compared to the nonimpaired probands $[16,17]$. Conversely, delay discounting failed to predict relapse, regardless of both probes sharing similar neuropsychological demands [18]. Although these findings illustrate the predictive power of decisionmaking skills on drug relapse, some limitations warrant further investigation. In the Bowden-Jones et al. [16] study, the alcohol patients who relapsed had higher baseline impulsivity scores compared to abstainers, which may have confounded the results. Furthermore, in the study of Passetti et al. [17], opiate users were receiving substitution pharmacotherapy; therefore, the results may not apply to drug-free individuals attempting to maintain abstinence. A more general consideration relates to the representativeness of the samples. Patients demanding treatment in Europe are characterized primarily by polysubstance dependence and comorbid psychopathology, variables that previous studies have not considered. The effect of these variables should also be dissociated from the contribution of other sociodemographic and clinical factors.

We therefore aimed to study the role of delay-discounting, as measured by the Delay Discounting Task (DDT), and decision-making skills, as measured by the IGT, on predicting 3-month drug relapse in a sample of drug-free polysubstance-dependent alcoholics (PSA). Both neurocognitive tasks have been frequently used. They are ecologically valid and believed to capture independent aspects of impulsivity. The selected group of addicted patients is representative of the general population of patients demanding treatment in Europe [19] for whom it is difficult to cease substance use [20,21]; therefore, we expected to find a substantial percentage of relapse during the first 3 months of abstinence. Moreover, PSA usually have comorbid personality disorders (PD), which influences decision-making $[22,23]$. Accordingly, we included comorbid PD patients in the target sample to increase its clinical representativeness. We used a longitudinal outcome study to examine the effect of delay discounting and decision-making, along with sociodemographic, clinical (personality disorders), and psychological variables (sensitivity to reward/punishment and trait impulsivity), on 3-month relapse. We predicted that the examined neurocognitive measures would have a direct effect on 3-month relapse. Clinical and psychological variables were examined as confounding variables, since they are known to affect addictions negatively. These variables thus might add to the effects of the neurocognitive tasks.

\section{Subjects and Methods}

\section{Participants}

Thirty-seven PSA were recruited from an addiction ward (Psychiatric Center Broeders Alexianen, Boechout, Belgium) based on the following criteria: age (18-55) and lifetime dependence on at least three substances with the exception of caffeine and nicotine (table 1). Participants were excluded when they showed signs of lifetime psychotic disorders (sources: clinical psychiatric Interview, Structured Clinical Interview for DSM disorders), organic deterioration or amnesic disorders, physical handicaps, severe somatic disorders, illiteracy, or mental retardation. 


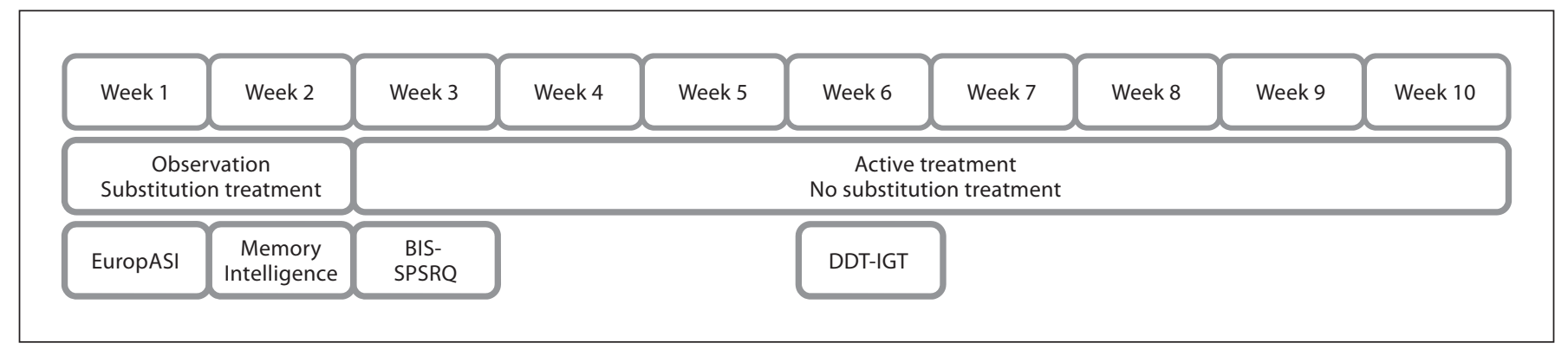

Fig. 1. Research procedure.

\section{Sociodemographic, Clinical and Background Cognition} Measures

- The European version of the Addiction Severity Index (EuropASI) [24] was used to assess patients' substance use before the treatment. At follow-up, the alcohol and drug sections of the follow-up version of the EuropASI were used to determine whether PSA were abstainers or nonabstainers. The data were converted into dichotomous variables. PSA were considered abstinent if they reported no substance use (apart from caffeine and nicotine), while those who reported using substances in addition to caffeine and nicotine were considered relapsed.

- The Assessment of DSM-IV Personality disorders (ADP-IV) $[25,26]$ is a self-report questionnaire comprising 94 phrases. Each phrase represents a DSM-IV axis-II criterion. Each phrase is measured on a seven-point Likert scale to form a trait score: How much do you agree with this statement about yourself? Answers: 1 = totally disagree; 2 = disagree; $3=$ tend to disagree; $4=$ neither agree nor disagree; $5=$ tend to agree; $6=$ agree; 7 = fully agree. Typical criteria (trait score $\geq 5$ ) are further judged on a three-point Distress scale: Has this trait ever caused you or others any suffering or problems? Answers: $1=$ not at all; $2=$ to a degree; $3=$ definitely. The T'5 (Trait score $\geq 5$ ) and D'1 (Distress score $\geq 1$ ) categorical diagnostic evaluation algorithm was used to state the presence of DSM-IV axis-II criteria. The diagnoses were made based on the presence of the DSM-IV criteria.

- The Raven Progressive Matrices (Raven PM) [27] and the Rey Auditory Verbal Learning Test (AVLT) [28] were used to estimate intelligence and verbal memory.

\section{Self-Report Measures of Impulsive Personality}

- The Barratt Impulsiveness Scale (BIS) [29], a self-report questionnaire (30 items), measured total, attentional, motor, and nonplanning facets of trait impulsivity.

- The Sensitivity to Punishment and Sensitivity to Reward Questionnaires (SPSRQ) [30] measured personality traits associated with the behavioral activation or appetitive system (sensitivity to reward) and the behavioral inhibition system (sensitivity to punishment).

Cognitive Measures of Impulsivity and Decision-Making

- A computerized version of the DDT [31] asked participants to choose between immediate (USD 10, 30 and 100) and delayed rewards (values adapted according to an adjusting amount procedure). The delays were set at 2, 30, 180, 360 or 720 days.

- IGT [based upon 14, 32] required participants to choose 100 cards from four card decks (K', L', M', N'). Each deck held 60 cards with identical backs. Participants were instructed to select cards to earn as much money as possible. Unknown to them, card selections came with different pay-offs: good decks (K'M') combined modest wins with small losses (net gains) while bad decks (L', N') combined large wins with even larger losses (net losses). Good decks gave net gains while bad decks led to net losses. Outcome measures were the mathematical differences between the number of cards picked from the advantageous decks and the number of cards picked from the disadvantageous decks, calculated for blocks of 20 cards. The K'L'M'N'version is more difficult than the original ABCD and A'B'C'D' version because it uses all pay-offs instead of simple multiplications of ten.

\section{Procedure (fig. 1)}

PSAs who entered the ward consecutively were asked about their substance use. A week later, verbal memory and intelligence were assessed. When they were abstinent for two weeks, PSAs completed the BIS and the SPSRQ. The DDT and the IGT were performed when PSAs were abstinent for 6 weeks. Regular urine screens were used to confirm abstinence. Three months after the treatment, PSAs were asked about their last-month substance use. They were considered abstinent if they reported no substance use (apart from caffeine and nicotine) (abstainers). They were considered relapsers if they used substances other than caffeine and nicotine (nonabstainers). Participants gave written informed consent.

The ethical committee of the University of Antwerp approved the procedure.

\section{Data Analytic Plan}

This naturalistic outcome study compared two groups of individuals, abstinent and nonabstinent from alcohol and or illicit drugs, at three months. $t$ and $\chi^{2}$ tests were used to examine group differences in demographic, substance use, and personality disorders variables. Group differences in personality traits (BISSPSRQ) were found through general linear model (GLM) multivariate analyses. Group differences in neurocognitive measures (DDT-IGT) were tested with ANOVAs (GLM repeated measures). 


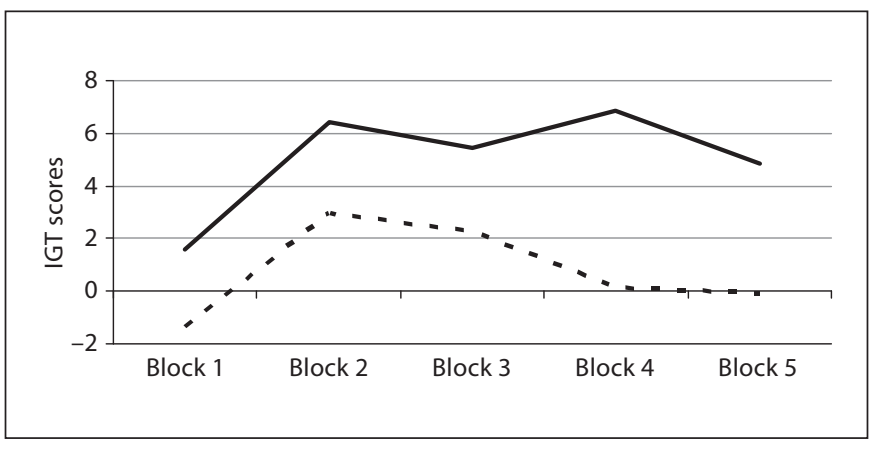

Fig. 2. IGT performances in abstainers (-) and nonabstainers $(--)$.

Possible effects of the PD on the impulsivity and neurocognitive measures were examined by adding the PD (absent/present based upon the ADP-IV) as additional independent variable in the analyses. None of these analyses changed the present findings. These data can be provided on simple request to the first author.

\section{Results}

\section{Demographic Variables}

At follow-up, 11 males and 3 females were classified as abstainers while 18 males and 5 females were classified as nonabstainers. Mean age of both abstainers and nonabstainers was 32 years. They both went to school for 11 years. Abstainers $(n=14)$ and nonabstainers $(n=23)$ thus did not differ on demographic variables (table 2).

\section{Substance Use, Clinical and Background Cognition}

Variables (table 2)

Abstainers and nonabstainers used alcohol and drugs for 15 years. However, abstainers were slightly older than nonabstainers when they started to use alcohol and drugs (marginally significant effect). The severity of their substance was similar.

As shown in table 2, abstainers and nonabstainers differed in cluster C PD presence. PD presence or absence did not affect the self-report measures of impulsive personality or the cognitive measures of impulsivity and decision-making.

The groups finally did not differ on the AVLT and Raven PM (table 2).

Self-Report Measures of Impulsive Personality (table 2)

As seen in table 2, abstainers and nonabstainers did not differ in BIS and SPSRQ scores.
Table 2. Differences in demographic variables, substance use, clinical and background cognition measures, self-report measures of impulsive personality and cognitive measures of impulsivity and decision-making in PSA abstainers $(\mathrm{n}=14)$ vs. PSA nonabstainers $(\mathrm{n}=23)$

\begin{tabular}{lccc}
\hline Variables & Abstainers & Nonabstainers & $\begin{array}{l}\mathrm{p} \\
\text { values }\end{array}$ \\
\hline Gender & $11 \delta / 3$ q & 18 s/ 5 q & NS \\
Cluster A PD & 2 yes/12 no & 5 yes/18 no & NS \\
Cluster B PD & 7 yes/7 no & 7 yes/16 no & NS \\
Cluster C PD & 5 yes/9 no & 2 yes/21 no & $<0.050$ \\
Age & $32.21 \pm 5.32$ & $31.68 \pm 7.88$ & NS \\
Years of education & $11.36 \pm 2.17$ & $11.41 \pm 2.56$ & NS \\
Age of onset & $16.71 \pm 4.70$ & $14.45 \pm 2.30$ & $<0.100$ \\
Years of substance use & $14.57 \pm 6.25$ & $15.36 \pm 6.46$ & NS \\
EuropASI-alcohol & $4.57 \pm 3.03$ & $4.74 \pm 2.78$ & NS \\
EuropASI-drug & $5.14 \pm 1.61$ & $5.39 \pm 1.78$ & NS \\
Raven PM & $46.21 \pm 2.08$ & $49.96 \pm 1.62$ & NS \\
AVLT & $106.43 \pm 3.70$ & $110.17 \pm 2.89$ & NS \\
BIS-total & $76.86 \pm 11.12$ & $78.26 \pm 9.12$ & NS \\
BIS-attention & $19.00 \pm 4.30$ & $19.91 \pm 4.10$ & NS \\
BIS-motor & $26.29 \pm 5.90$ & $26.48 \pm 3.64$ & NS \\
BIS-nonplanning & $31.57 \pm 4.01$ & $31.87 \pm 4.17$ & NS \\
SPSRQ-SP & $13.93 \pm 7.18$ & $12.65 \pm 6.18$ & NS \\
SPSRQ-SR & $14.14 \pm 4.66$ & $12.57 \pm 4.27$ & NS \\
DDT-k-log & & & NS \\
$\quad$ 10 USD & $-1.42 \pm 0.65$ & $-1.57 \pm 0.79$ & \\
$\quad$ 30 USD & $-1.40 \pm 0.61$ & $-1.63 \pm 0.92$ & \\
$\quad 100$ USD & $-1.57 \pm 0.84$ & $-1.75 \pm 1.05$ & \\
\hline
\end{tabular}

Values denote numbers or means $\pm \mathrm{SD}$.

\section{Cognitive Measures of Impulsivity and}

\section{Decision-Making}

GLM repeated measures analyses of variance with Block (Block 1 to 5) as within-subjects factor and Group (abstainers-nonabstainers) as between-subjects factor showed that abstainers and nonabstainers differed in IGT $(\mathrm{F}(1,35)=5.264, \mathrm{p}=0.028)$. IGT performances also changed over Blocks $(\mathrm{F}(4,32)=3.684 ; \mathrm{p}=0.014)$. There was no significant block $\times$ group interaction effect $(\mathrm{F}(4,32)=0.299 ; \mathrm{p}=0.876)$ (fig. 2). GLM repeated measures analyses of variance with amount (USD 10-100) as within-subject factor and group (abstainers vs. nonabstainers) as between-subject factors showed that abstainers and nonabstainers did not differ in $\operatorname{DDT}(\mathrm{F}(1,33)=$ $0.422, \mathrm{p}=0.520)$. There also were no significant amount $(\mathrm{F}(2,32)=2.534 ; \mathrm{p}=0.087)$ or amount $\times$ group interaction effects $(\mathrm{F}(2,32)=0.107 ; \mathrm{p}=0.898)$. Correlations be- 
Table 3. Correlations between neurocognitive measures and other important variables

\begin{tabular}{|c|c|c|c|c|c|c|c|c|}
\hline & Age & Onset & Duration & BIS & SPSRQ-SP & SPSRQ-SR & Log-k-100 & IGT \\
\hline Age & 1.000 & 0.175 & $0.670^{* *}$ & -0.143 & 0.081 & 0.130 & -0.200 & -0.112 \\
\hline Duration & & & 1 & -0.059 & 0.147 & 0.250 & -0.216 & -0.106 \\
\hline BIS & & & & 1.000 & 0.318 & 0.103 & 0.119 & -0.109 \\
\hline SPSRQ-SP & & & & & 1.000 & 0.052 & 0.142 & -0.095 \\
\hline log-k-100 & & & & & & & 1.000 & 0.020 \\
\hline IGT & & & & & & & & 1.000 \\
\hline
\end{tabular}

Onset = Age of onset; duration = years of substance dependence; BIS = total score of the Barratt Impulsiveness Scale; SPSRQ-SP/ SPSRQ-SR = Sensitivity to Punishment and Sensitivity to Reward Questionnaires-Sensitivity to Punishment/Sensitivity to Reward; log-k-100 = outcome measure of the DDT; IGT = Iowa Gambling Task net score (compound score over the blocks).

${ }^{*} \mathrm{p}<0.010 ;{ }^{* *} \mathrm{p}<0.001$.

tween neurocognitive tasks and other important variables are found in table 3. Using these variables as covariates did not influence the main results.

\section{Discussion}

The main result of the present study is that decisionmaking rather than delay discounting was associated with a 3-month abstinence in PSA. Psychological and clinical variables did not differ between abstainers and nonabstainers, thus increasing the specificity of prediction related to cognitive variables, in agreement with our initial hypothesis.

The subset of patients who relapsed into substance abuse within 3 months after the treatment had poorer decision-making performance compared to the patients who succeeded in maintaining abstinence. This is consistent with previous research showing that relapsed alcohol [16] and opiate-dependent patients [17] performed significantly worse compared to nonrelapsed patients on neurocognitive probes at the 3 -month follow-up. However, alcohol abstainers in the Bowden-Jones et al. [16] study had lower baseline impulsivity scores, which is a relevant confounder considering that low trait impulsivity is significantly predictive of better decision-making performance on the IGT [33]. In addition, the opiatedependent patients included in the study of Passetti et al. [17] were all stabilized on substitute opiate pharmacotherapy, which is known to affect decision-making skills [34], and may therefore influence outcome results. A number of other studies on cognitive predictors of outcome, which have been developed in the context of clinical trials testing CNS-active medications, share this limitation [4]. In view of these specifications, our study is the first to demonstrate that decision-making skills predict drug relapse in previously stably abstinent (drugfree) polysubstance abusers, irrespective of the influence of personality traits and co-existent medications. The present study is also first to demonstrate that decisionmaking is a reliable predictor of relapse even when abstainers and nonabstainers are equally impulsive. This finding is in line with data on pathological gamblers [35].

The finding that the abstainers and nonabstainers did not differ on delay discounting conflicts with our initial hypotheses but is consistent with the data of Passetti et al. [17] showing that a 3-month abstinence was not associated with DDT performances in a group of opiatedependent patients. Although both tasks have shown to correlate significantly [18], a number of factors can account for the variation in their predictive value. First, unlike the DDT, the IGT factors in a number of aspects that are more representative of real-life decision-making, including immediate rewards confronted by the prospect of potential punishments and decisions involving both risk and uncertainty of outcomes. These aspects are thought to increase the ecological validity of the IGT and its ability to predict specific problems pertaining to addicted populations [36]. A second factor relates to the notion that the DDT assesses choices between short and long-term outcomes, whereas the IGT 
assesses choices between outcomes with particular probabilities [18]. One might hypothesize that the processes involved in the DDT are more important to the early stages of addiction, when people are driven by attractive short-term effects, but relatively blind to the long-term, less-attractive effects of substance use. Conversely, the processes involved in the IGT are more important to the latter stages of addiction, when people understand the likelihood of the short- and long-term consequences of drug use but may have problems adjusting motivational preferences to expected outcomes $[37,38]$. In agreement with this notion, the findings demonstrated that impulsive action was associated with the initiation/maintenance of nicotine self-administration in rats while impulsive choice was associated with diminished abilities to withhold nicotine reinstatement [39]. Impulsive action hereby refers to poor inhibitory control resulting from deficits in the ability to withhold responding while impulsive action refers to impulsive decision-making resulting from an insensitivity to delay of gratification or aversion. Germane to this, different strands of evidence also suggest that difficulties in reversal learning can explain impaired IGT performances $[37,40]$, meaning that participants do not shift their preferences away from the initially rewarding decks to the latter rewarding decks. This agrees with recent views of the neurocircuitry of the addictive processes, which is thought to transit from impulsivity (choices guided by acute reinforcement) to compulsivity (inability to reverse habitual response patterns). These models, however, are found mainly in animal literature [41, 42].

As in other studies, we found a high comorbidity with co-occurring personality disorders in our clinical sample $[43,44]$. Interestingly, cluster B diagnosis did not increase the risk of drug relapse, despite it being traditionally considered an important clinical variable with a negative effect on treatment outcome [44]. Therefore, our data support the hypothesis that underlying cognitive skills rather than heterogeneous clinical syndromes or estimates of problem severity (e.g. ASI scores) are better predictors of maintaining abstinence. Along the same lines, the finding that more patients with a cluster $\mathrm{C}$ personality disorder did succeed abstinence is consistent with the data of Werner et al. [45] showing better decision-making performances in high trait anxiety participants. These researchers suggested an inverted U-shape association between trait anxiety (the main characteristic of this cluster) and decision-making. To incorporate the data of Miu et al. [46], they argued that patients with both low and extreme trait anxiety tend to show poor decision-making performance, whereas patients with moderate anxiety tend to have superior decision-making skills. Our group thus seemed to obtain intermediate scores.

Overall, our results add to the evidence that deficits in IGT performances are associated with a higher risk of relapse and poor outcomes among substance-dependent patients. As of yet, it remains unclear whether these deficits reflect premorbid vulnerability factors or the effects of the neurotoxicity due to the prolonged and intensive substance use. To support the former, research findings show an association between deficits in behavioral measures of impulsivity and addictive behaviors in adolescents some years after administering the behavioral measures [47-49]. In support of the latter hypothesis, recent findings in animal studies demonstrated that decisionmaking deficits were a direct result of consuming high levels of alcohol during adolescence [50]. Whether these results can be extrapolated to adult substance abusers remains to be explored.

Our findings may have important clinical implications. First, they underline the importance of using neurocognitive measures when identifying high relapse risk patients in clinical populations. Second, they stress the relevance of promoting new treatment interventions, both pharmacological and psychosocial, targeted at strengthening decision-making abilities [51].

The main strength of the study is that it used a large sample representative of current real-world clinical populations [52]. This implies that the present findings can not only be used easily in clinical practice, but they can also be generalized to an important number of substance-dependent patients in need of effective treatments $[20,21]$. An additional strength of the present study is the inclusion of many possible confounding variables, like the PD, which have been found to relate to the decisionmaking variables [53-55]. A possible weakness of the present study is the choice of the outcome parameter. In line with the EuropASI follow-up, relapse was defined as any substance use within the last 30 days prior to the follow-up interview. This approach originates from the idea that substance-dependent patients either relapse soon after the end of their treatment or do not relapse at all $[56,57]$. In our study, 2 patients relapsed soon after the end of the treatment but attained abstinence in the last month prior to the follow-up interview. We made the analyses with and without those 2 patients and found similar results. We thus believe that the choice of our outcome parameter, which has been used in comparable research, is justified $[16,17]$. Further, we did not perform urine analyses at the follow-up interview. However, 
whenever possible, patient reports were compared to relatives' reports, and since these reports were in agreement with each other, it was believed that patients' reports of substance use were accurate. Though we checked for many confounding variables, we did not manage to cap- ture them all. Craving, a factor known to affect relapse, could be a confounding variable that we did not include in our analysis. Thus, future research should consider craving and other factors mentioned in the study of Reske and Paulus [1].

\section{References}

1 Reske M, Paulus MP: Predicting treatment outcome in stimulant dependence. Ann NY Acad Sci 2008;1141:270-283.

$>2$ Aharonovich E, Nunes E, Hasin D: Cognitive impairment, retention and abstinence among cocaine abusers in cognitive-behavioral treatment. Drug Alcohol Depen 2003; 71:207-211.

-3 Aharonovich E, Hasin DS, Brooks AC, Liu XH, Bisaga A, Nunes EV: Cognitive deficits predict low treatment retention in cocaine dependent patients. Drug Alcohol Depen 2006;81:313-322.

$\checkmark 4$ Streeter CC, Terhune DB, Whitfield TH, Gruber S, Sarid-Segal O, Silveri MM, Tzilos G, Afshar M, Rouse ED, Tian H, Renshaw PF, Ciraulo DA, Yurgelun-Todd: Performance on the Stroop predicts treatment compliance in cocaine-dependent individuals. Neuropsychopharmacology 2008;33:827-836.

$>5$ George O, Koob GF: Individual differences in prefrontal cortex function and the transition from drug use to drug dependence. Neurosci Biobehav Rev 2010;35:232-247.

$\checkmark 6$ Fernandez-Serrano MJ, Perez-Garcia M, Verdejo-Garcia A: What are the specific versus generalized effects of drugs of abuse on neuropsychological performance? Neurosci Biobehav Rev 2011;35:377-406.

$>7$ Fein G, Klein L, Finn P: Impairment on a simulated gambling task in long-term abstinent alcoholics. Alcohol Clin Exp Res 2004; 28:1487-1491.

$>8$ Hoffman WF, Moore M, Templin R, McFarland B, Hitzemann RJ, Mitchell SH: Neuropsychological function and delay discounting in methamphetamine-dependent individuals. Psychopharmacology 2006;188: $162-170$.

9 Verdejo-Garcia A, Rivas-Perez C, Vilar-Lopez R, Perez-Garcia M: Strategic self-regulation, decision-making and emotion processing in poly-substance abusers in their first year of abstinence. Drug Alcohol Depen 2007;86:139-146.

-10 Tanabe J, Tregellas JR, Dalwani M, Thompson L, Owens E, Crowley T, Banich M: Medial orbitofrontal cortex gray matter is reduced in abstinent substance-dependent individuals. Biol Psychiatry 2009;65:160-164.

-11 Verdejo-Garcia A, Bechara A: A somatic marker theory of addiction. Neuropharmacology 2009;56:48-62.
12 Sinha R, Garcia M, Paltawal P, Kreek MJ, Rounsaville BJ: Stress-induced cocaine craving and hypothalamic-pituitary-adrenal responses are predictive of cocaine relapse outcomes. Arch Gen Psychiatry 2006;63: 324-331.

13 Epstein DH, Wilner-Reid J, Vahabzadeh M, Mezghanni M, Lin J-L, Preston KL: Realtime electronic diary reports of cue exposure and mood in the hours before cocaine and heroin craving and use. Arch Gen Psychiatry 2009;66:88-94.

14 Bechara A, Damasio AR, Damasio H, Anderson SW: Insensitivity to future consequences following damage to human prefrontal cortex. Cognition 1994;50:7-15.

15 Rogers RD, Everitt BJ, Baldacchino AM, Blackshaw AJ, Swainson R, Wynne K, Baker NB, Hunter J, Carthy T, Booker E, London M, Deakin JFW, Sahakian BJ, Robbins TW: Dissociable deficits in the decision-making cognition of chronic amphetamine abusers, opiate abusers, patients with focal damage to prefrontal cortex, and tryptophan-depleted normal volunteers: evidence for monoaminergic mechanisms. Neuropsychopharmacology 1999;20:322-339.

16 Bowden-Jones H, McPhillips M, Rogers R, Hutton S, Joyce E: Risk-taking on tests sensitive to ventromedial prefrontal cortex dysfunction predicts early relapse in alcohol dependency: a pilot study. J Neuropsychiatry Clin Neurosci 2005; 17:417-420.

17 Passetti F, Clark L, Mehta MA, Joyce E, King M: Neuropsychological predictors of clinical outcome in opiate addiction. Drug Alcohol Depen 2008;94:82-91.

18 Monterosso J, Ehrman R, Napier KL, O’Brien $\mathrm{CP}$, Childress AR: Three decision-making tasks in cocaine-dependent patients: do they measure the same construct? Addiction 2001;96:1825-1837.

19 European Monitoring Centre for Drugs and Drug Addiction: Selected issue 2009. Polydrug Use: Patterns and Responses. Luxembourg, Publications Office of the European Union, 2009.

20 Dutra L, Stathopoulou G, Basden SL, Leyro TM, Powers MB, Otto MW: A meta-analytic review of psychosocial interventions for substance use disorders. Am J Psychiatry 2008; 165:179-187.
21 Karno MP, Grella CE, Niv N, Warda U, Moore AA: Do substance type and diagnosis make a difference? A study of remission from alcohol- versus drug-use disorders using the national epidemiologic survey on alcohol and related conditions. J Stud Alcohol Drugs 2008;69:491-495.

22 Dom G, De Wilde B, Hulstijn W, Van Den Brink W, Sabbe B: Decision-making deficits in alcohol-dependent patients with and without comorbid personality disorder. Alcohol Clin Exp Res 2006;30:1670-1677.

23 Vassileva J, Petkova P, Georgiev S, Martin EM, Tersiyski R, Raycheva M, Velinov V, Marinov $\mathrm{P}$ : Impaired decision-making in psychopathic heroin addicts. Drug Alcohol Depen 2007;86:287-289.

24 Raes V, Lombaert G, Keymeulen R: De Nederlandse vertaling van de handleiding voor training en afname van EuropASI vraaggesprekken, aangepast voor BelgiëVlaanderen, met integratie van de Treatment Demand Indictor. Versie 2008. Gent, De Sleutel Dienst Wetenschappelijk Onderzoek, 2008.

25 Schotte C, De Doncker D: ADP-IV Questionnaire. Antwerp, University Hospital Antwerp, 1994.

26 Schotte C, De Doncker D: ADP-IV Questionnaire: Manual and Norms. Antwerp, University Hospital Antwerp, 1996.

27 Raven JC: Mental tests used in genetic studies: the performance of related individuals on tests mainly educative and mainly reproductive. MSc Thesis, University of London, 1936.

28 Lezak M (ed): Neuropsychological Assessment. New York, Oxford University Press, 2004.

29 Patton JH, Stanford MS, Barratt ES: Factor structure of the Barratt Impulsiveness Scale. J Clin Psychol 1995;51:768-774.

30 Torrubia R, Avila C, Molto J, Caseras X: The sensitivity to punishment and sensitivity to reward questionnaires (SPSRQ) as a measure of Gray's anxiety and impulsivity dimensions. Pers Indiv Differ 2001;31:837862.

31 Richards JB, Zhang L, Mitchell SH, de Wit H: Delay or probability discounting in a model of impulsive behaviour: effect of alcohol. J Exp Anal Behav 1999;71:121-143. 
-32 Verdejo-Garcia A, Bechara A, Recknor C, Perez-Garcia M: Decision-making and the Iowa Gambling Task: ecological validity in individuals with substance dependence. Psychol Belg 2006;46:55-78.

33 Upton DJ, Bishara AJ, Ahn WY, Stout JC Propensity for risk taking and trait impulsivity in the Iowa Gambling Task. Pers Indiv Differ 2011;50:492-495.

34 Pirastu R, Fais R, Messina M, Bini V, Spiga S, Falconieri D, Diana M: Impaired decisionmaking in opiate-dependent subjects: effects of pharmacological therapies. Drug Alcohol Depen 2006;83:163-168.

-35 Goudriaan AE, Oosterlaan J, de Beurs E, van den Brink W: The role of self-reported impulsivity and reward sensitivity versus neurocognitive measures of disinhibition and decision-making in the prediction of relapse in pathological gamblers. Psychol Med 2008; 38:41-50.

- 36 Verdejo-Garcia A, Bechara A, Recknor EC, Perez-Garcia M: Decision-making and the Iowa Gambling Task: ecological validity in individuals with substance dependence. Psychol Belg 2006;46:55-78.

37 Dunn BD, Dalgleish T, Lawrence AD: Review - the somatic marker hypothesis: a critical evaluation. Neurosci Biobehav Rev 2006; 30:239-271.

- 38 Rubio G, Jimenez M, Rodriquez-Jimenez R, Martinez I, Avila C, Ferre F, Jimenez-Arriero MA, Ponce G, Palomo T: The role of behavioral impulsivity in the development of alcohol dependence: a 4-year follow-up study. Alcohol Clin Exp Res 2008;32:1681-1687.

-39 Diergaarde L, Patty T, Poortvliet I, Hogenboom F, de Vries W, Schoffelmeer ANM, De Vries TJ: Impulsive choice and impulsive action predict vulnerability to distinct stages of nicotine seeking in rats. Biol Psychiatry 2008;63:301-308.
40 Fellows LK, Farah MJ: Dissociable elements of human foresight: a role for the ventromedial frontal lobes in framing the future, but not in discounting future rewards. Neuropsychologia 2005;43:1214-1221.

41 Everitt BJ, Robbins TW: Neural systems of reinforcement for drug addiction: from actions to habits to compulsion. Nat Neurosci 2005;8:1481-1489.

42 Koob GF, Volkow ND: Neurocircuitry of addiction. Neuropsychopharmacology 2010; 35:217-238.

43 Trull TJ, Sher KJ, Minks-Brown C, Durbin J, Burr R: Borderline personality disorder and substance disorders: a review and integration. Clin Psychol Rev 2000;20:235-253.

44 Verheul R, Van den Brink W: Causal pathways between substance use disorders and personality pathology. Aust Psychol 2005; 40:127-136

45 Werner NS, Duschek S, Schandry R: Relationships between affective states and decision-making. Int J Psychophysiol 2009;74: 259-265.

46 Miu AC, Heilman RM, Houser D: Anxiety impairs decision-making: psychophysiological evidence from an Iowa Gambling Task. Biol Psychol 2008;77:353-358.

47 Ernst M, Luckenbaugh DA, Moolchan ET, Leff MK, Allen R, Eshel N, London ED, Kimes A: Behavioral predictors of substance-use initiation in adolescents with and without attention deficit/hyperactivity disorder. Pediatrics 2006;117:2030-2039.

48 Ivanov I, Schulz KP, London ED, Newcorn $\mathrm{JH}$ : Inhibitory control deficits in childhood and risk for substance use disorders: a review. Am J Drug Alcohol Ab 2008;34:239258 .

49 Vitaro F, Arseneault L, Tremblay RE: Impulsivity predicts problem gambling in low SES adolescent males. Addiction 1999;94:565575.
50 Nasrallah NA, Yang TWH, Bernstein IL: Long-term risk preference and suboptimal decision making following adolescent alcohol use. Proc Natl Acad Sci USA 2006;106: 17600-17604.

51 Alfonso P, Caracuel A, Delgado-Pastor LC, Verdejo-Garcia A: Combined goal management training and mindfulness meditation improve executive functions and decisionmaking performance in abstinent polysubstance abusers. Drug Alcohol Depen 2011; 117:78-81.

52 Rounsaville BJ, Petry NM, Carroll KM: Single versus multiple drug focus in substance abuse clinical trials research. Drug Alcohol Depen 2003;70:117-125.

53 Haaland VO, Landro NI: Decision making as measured with the Iowa Gambling Task in patients with borderline personality disorders. J Int Neuropsychol Soc 2007;13:699703.

54 Ruocco AC, McCloskey MS, Lee R, Coccaro EF: Indices of orbitofrontal and prefrontal function in cluster B and cluster C personality disorders. Psychiatry Res 2009;170:282285 .

55 Völlm B, Richardson P, McKie S, Elliot R, Dolan M, Deakin B: Neuronal correlates of reward and loss in cluster B personality disorders: a functional magnetic resonance imaging study. Psychiatry Res 2007;156:151167.

56 McLellan AT, Lewis DC, O’Brien CP, Kleber HD: Drug dependence, a chronic medical illness. Implications for treatment, insurance and outcome evaluation. J Am Med Assoc 2000;284:1689-1695.

57 Sellman D: The 10 most important things known about addiction. Addiction 2010;105: 6-13. 